\section{Talc as Reinforcing Filler in Polypropylene Compounds: Effect on Morphology and Mechanical Properties}

\section{Abstract}

Talc represents one of the most useful mineral fillers which are compatible with the polypropylene (PP). It is characterized with its lamellar structure. The introduction of $30 \%$ by weight of talc, three types differing with the particle size $d_{50}$ and the composition, has not only a positive influence on stiffness and crystallinity but also it decreases the impact strength and tenacity. The abrasive wear behavior depends mainly on the particle size of talc. Microscopic observations revealed that the talc layers are aligned along the injection flow direction, and uniformly dispersed in the PP matrix.

Keywords: Polypropylene; Talc filler; Compound; Mechanical reinforcement; Wear resistance

Received: July 01, 2017; Accepted: July 10, 2017; Published: July 20, 2017

\section{Ammar O*, Bouaziz Y, Haddar $\mathbf{N}$ and Mnif $\mathbf{N}$ \\ Laboratoire Génie des Matériaux et Environnement, ENIS, B.P 1173, 3038 Université de Sfax, Tunisia}

\section{*Corresponding author: Ons Ammar \\ ammar_ons@yahoo.fr}

Laboratoire Génie des Matériaux et Environnement, ENIS, B.P 1173, 3038 Université de Sfax, Tunisia.

Tel: +21622789722

\section{Citation: Ammar O, Bouaziz Y,} Haddar N, Mnif N (2017) Talc as Reinforcing Filler in Polypropylene Compounds: Effect on Morphology and Mechanical Properties. Polym Sci. Vol. 3 No. 1:8

\section{Introduction}

Polypropylene (PP) is one of the most extensively produced polymers, especially widely used as automotive parts due to its good impact resistance as well as processability [1]. The addition of fillers into PP matrix has been an accepted route to achieve enhancement in material properties or/and cost saving possibilities. Talc, a plate-like layered structure magnesium silicate mineral, in which the octahedral brucite layer is sandwiched between two tetrahedral silica sheets, has proved to be particularly efficient filler on the mechanical properties and macromolecular orientation of compounds [2-6] and consequently an increase of the performance of reinforced polymeric matrix. At low concentrations (less than 3 weight\%), talc acts as a nucleating agent, reducing spherulite size and shortening processing time [7]. At higher loadings (10-40 weight\%) it acts as a reinforcing filler, increasing tensile modulus and stiffness, but reducing strain-to break and impact strength [8]. However, it has been highlighted that the filler nature of talc influences its reinforcement ability, depending on the surface activity, particle size, surface area, and surface functional groups [9-10].

This study concerns the effect of the addition of mineral filler (30\% of talc) in polypropylene matrix on the morphological and mechanical properties. Three types of compounds PP/Talc (with $30 \%$ by weight of talc), differing by composition and average particle size, were used in this investigation. The crystallization and melting behaviour of PP and compounds was studied by differential scanning calorimetry (DSC) while the fracture surface morphology of the samples was studied under scanning electron microscope (SEM). Mechanical testing such as tensile, impact, resilience and abrasion tests were also done in order to determine the mechanical properties of compounds.

\section{Experimental Procedure}

\section{Materials}

The investigated polypropylene homopolymer was Moplen HP500N with a melt flow index of $12 \mathrm{~g} / 10 \min \left(230^{\circ} \mathrm{C}, 2.16 \mathrm{~kg}\right)$ and a density of $0.9 \mathrm{~g} / \mathrm{cm}^{3}$. Three types of talc were used in this study; they differ with the average diameter $d_{50}$ and composition. The average particle size $d_{50}$ represents the median of the Gaussian distribution form of particles (Figure 1).They were incorporated in the PP matrix with the same percentage (30\%). The main characteristics of talc are shown in Table 1 . The three compounds PP/talc contain carbon black with a rate of $1 \%$ in maximum.

Blends of PP/talc were compounded on a twin screw extruder which warranted good dispersion of the filler in the polymer 
matrix. No surface treatments were used on the talc. The extruded blend was injection moulded into specimens for testing.

\section{Characterization methods}

Thermal testing: Differential Scanning Calorimetry measurements were conducted on PP and PP/Talc samples in order to determine the specific enthalpy and the temperatures of melting and crystallization. Thermal experiments were performed by heating from -50 to $250^{\circ} \mathrm{C}$ at a heating rate of $10^{\circ} \mathrm{C} / \mathrm{min}$ under dry nitrogen atmosphere. The value of specific melting enthalpy $\left(\Delta \mathrm{H}_{\mathrm{f}}\right)$ was determined from the area under the melting peak of the second scan and used for the degree of crystallinity (Xc), using the following equation:

$X_{c}(\%)=\frac{\Delta H_{f}}{(1-w) \times \Delta H_{f}^{0}} \times 100$

Where $\Delta H^{0}$ is the theoretical melting enthalpy for $100 \%$ crystalline polypropylene taken as $209 \mathrm{~J} / \mathrm{g}$ [11].

Microscopic examination: Scanning electron microscope (SEM) was used to study the morphologies of the different compounds. Samples were fractured in liquid nitrogen and fracture surfaces were coated with a thin layer $(12 \mu \mathrm{m})$ of gold before examination by SEM.

Mechanical testing: The uniaxial tensile tests were conducted using a Galbadini QUASAR10 testing machine (capacity of 10 $\mathrm{kN}$ ) at a constant cross-head speed of $50 \mathrm{~mm} / \mathrm{min}$ and at room temperature. The dimensions of tensile test samples were taken according to the NF ISO 527-2 as depicted in Figure 2a. All reported results were the averages of three measurements for each condition.

The apparatus of Charpy test (capacity of $5 \mathrm{~J}$ ) consists of a pendulum axe swinging at an unnotched sample. This test indicates how the material will respond to suddenly applied shock by measuring the amount of energy absorbed by the polymer during fracture.

The tenacity represents the material's resistance to the propagation of a crack or a default. The studied specimens, type SENT (Single Edge Notch Tensile), presented a lateral notch as showing in Figure $\mathbf{2 b}$. The specimens notched and pre-cracked were tested with a tensile test machine (displacement speed $2 \mathrm{~mm} / \mathrm{min}$ at room temperature). They differ with the size ' $a$ ', realized with a razor blade in order to have the finest slot. Three specimens with a different size ' $a$ ' were prepared to unfilled PP, PP/Talc1 and PP/Talc2 (Table 2). In order to evaluate the critical energy $\mathrm{J}_{\mathrm{IC}^{\prime}}$, the method of Locus was adopted.

Wear testing: In order to characterize the tribological properties of the studied material, abrasive wear test was carried out on a pin-on-disk machine. Parallelipedic samples with dimensions of $19.4 \times 18 \times 4 \mathrm{~mm}^{3}$ were used. They were brought into contact with an abrasive paper (P240, average particle diameter $75 \mu \mathrm{m}$ ) fixed on a rotating disc which the speed can be varied from 50 to $600 \mathrm{tr} / \mathrm{min}$. The applied normal load was $5 \mathrm{~N}$ and the test duration was in the range of $30 \mathrm{~s}$ to $4 \mathrm{~min}$. Pre-weight samples were fixed on a disk attached to an electric motor. The sliding speed of the disk was in the range of $50-100 \mathrm{tr} / \mathrm{min}$. Tests were carried out at room temperature under a lubricated condition using tape water in order to avoid tear of abrasive paper. For each specimen a new abrasive paper was used to obtain reproducible results. The samples were thoroughly dried carefully before weighting. A Mettler microbalance with an accuracy of $0.1 \mathrm{mg}$ was used to measure the weight of the samples before and after each test. Each value represents the average of three tests.

\section{Results and Discussion}

\section{Thermal properties}

All results deduced from the DSC thermograms are summarized in Table 3. The melting temperature doesn't be modified but the

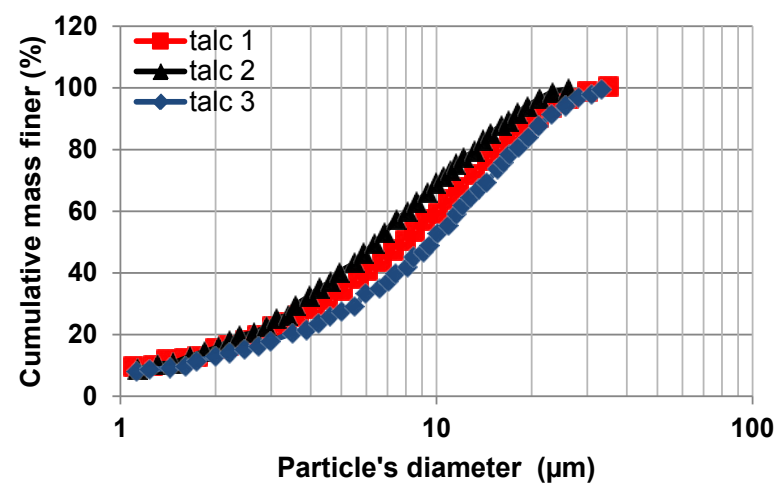

Figure 1 Cumulative grading curve for three different talc.

Table 1 Main characteristics of the three talc used in this investigation.

\begin{tabular}{r|c|c|c}
\hline \multirow{4}{*}{ Talc1 } & \multicolumn{1}{c}{ Composition $(\%)$} & $\mathbf{d}_{50}(\boldsymbol{\mu m})$ \\
& Talc+Chlorite & 98 & 8 \\
\multirow{2}{*}{ Talc2 } & Calcite+Dolomite & 2 & \\
& Talc+Chlorite & 80 & 6.6 \\
\multirow{2}{*}{ Talc3 } & Calcite+Dolomite & 20 & \\
& Talc+Chlorite & 70 & 9.5 \\
\hline
\end{tabular}

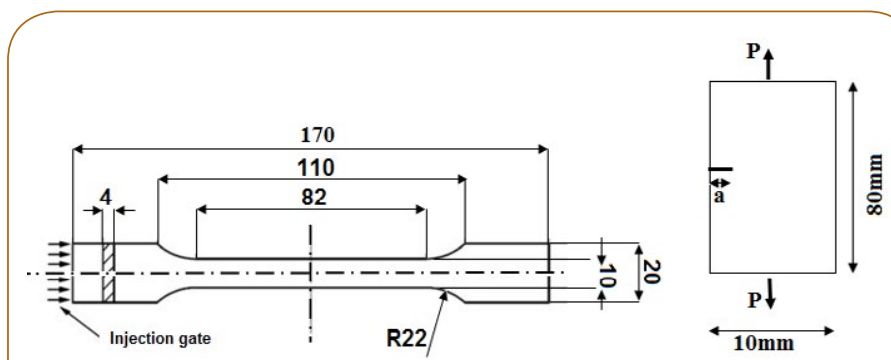

Figure 2 (a) ISO 527-2 type 1A standard sample (the unit is the $\mathrm{mm}$ ) and (b) SENT test specimen.

Table 2 Notch sizes used for tenacity tests.

\begin{tabular}{|c|c|c|c|}
\hline & Unfilled PP & PP/Talc1 & PP/Talc2 \\
\hline $\mathrm{a}_{1}(\mathrm{~mm})$ & 1.3 & 2.8 & 1.4 \\
\hline $\mathrm{a}_{2}(\mathrm{~mm})$ & 2.7 & 3.6 & 3.2 \\
\hline $\mathrm{a}_{3}(\mathrm{~mm})$ & 4.4 & 5.6 & 5.4 \\
\hline
\end{tabular}


crystallization one has been increased with $8^{\circ} \mathrm{C}$. The increase of crystallinity and the crystallization temperature indicates that the talc is a good nucleating agent. Therefore, the presence of talc particles causes an increase of nuclei density [12]. It was also noted the presence of a small peak for pre-fusion (at $112^{\circ} \mathrm{C}$ ) and another peak on the cooling's curve at $100^{\circ} \mathrm{C}$; it corresponds to a secondary crystallization. This result can be related to the presence of $\beta$-phase that isn't stable in the unfilled PP (Figure 3). Indeed, PP can crystallize in 4 polymorphic components: in $\alpha, \beta$ forms and more rarely in the $\gamma$ and $\delta$ forms. Fillers such as talc usually induce the $\alpha$ form in PP [12] and therefore, the disappearance of these two peaks has as origin the growth of $\alpha$-phase induced by talc, at the expense of $\beta$-phase.

Table 3 Melting and crystallization properties of PP phase in unfilled PP and PP/talc blends.

\begin{tabular}{|c|c|c|c|c|}
\hline & $\mathrm{T}_{\mathrm{f}}\left({ }^{\circ} \mathrm{C}\right)$ & $\mathrm{T}_{\mathrm{c}}\left({ }^{\circ} \mathrm{C}\right)$ & $\Delta \mathrm{H}_{\mathrm{f}}(\mathrm{J} / \mathbf{g})$ & $\mathbf{X}_{\mathrm{c}}(\%)$ \\
\hline Unfilled PP & 165 & 120 & 71.08 & 34.01 \\
\hline PP/Talc1 & 164 & 128 & 57.21 & 39.1 \\
\hline PP/Talc2 & 164 & 128 & 56.39 & 38.54 \\
\hline PP/Talc3 & 164 & 128 & 54.79 & 37.45 \\
\hline
\end{tabular}

\section{Scanning electron microscopy analysis}

Morphological observations by SEM (Figure 4) show that the three compounds don't differ in term of dispersion; the blends were compounded on a twin screw extruder that warrants a good dispersion of talc in PP matrix. It can be seen that talc's layers were aligned along the injection flow direction and uniformly dispersed in the matrix [13]. During injection moulding the platelets become aligned in the direction of the applied stress in the tensile specimen [14]. It was also noted the presence of some empty cavities in the interface PP/talc, it corresponds to the extraction of the carbon black's particles (nodular cavities) and of talc (platelets). This phenomenon shows that the interfacial adhesion between talc and PP seems poor for these three compounds. However, the compound PP/talc1, whose talc's particles are the finest, presents the best adhesion (Figure $4 \mathrm{a}$ ) compared to the others compounds (Figure $\mathbf{4 b}$ and 4c). The finer the charge, the higher is its specific surface area and, consequently, it offers better dispersion and adhesion with the polymeric matrix, and so a marked improvement in the properties of the compound.

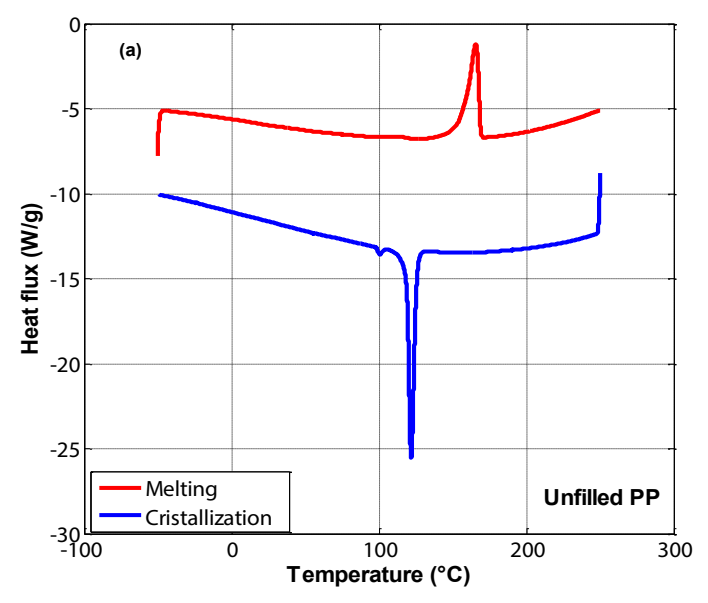

(a)

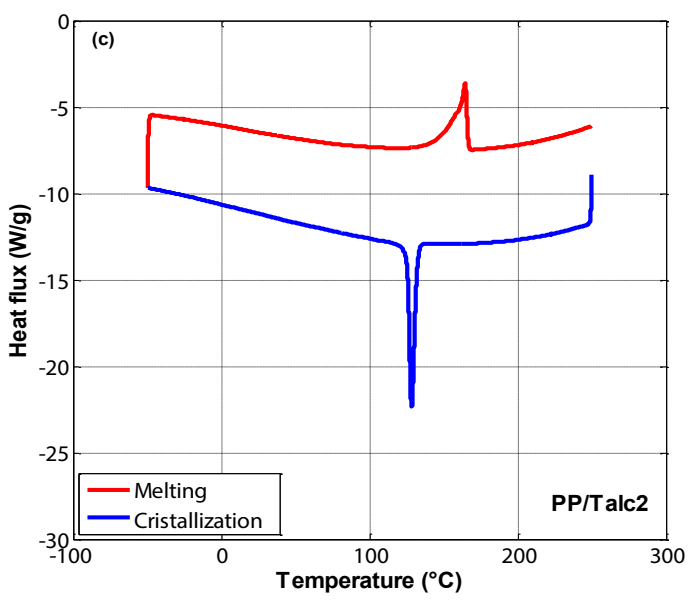

(c)

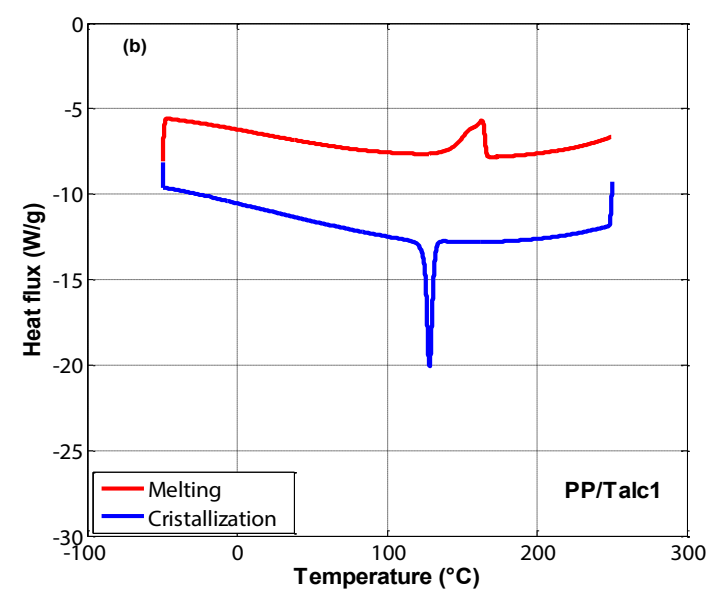

(b)

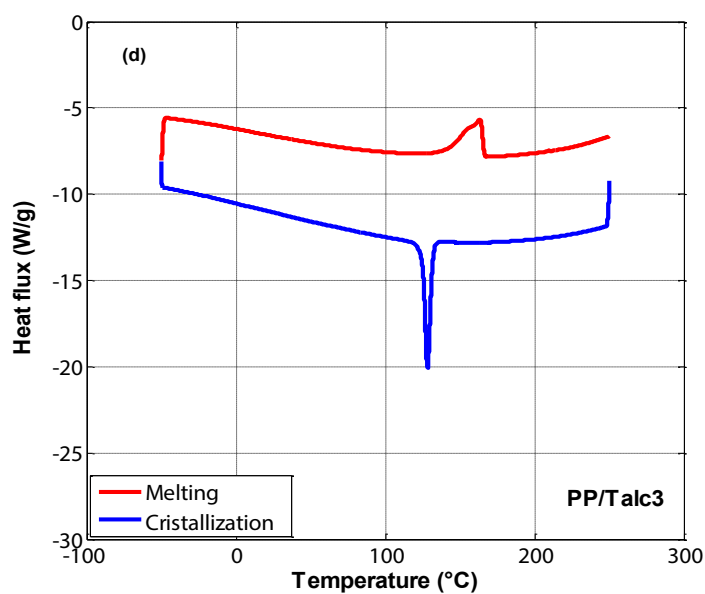

(d)

Figure 3 DSC thermograms of (a) unfilled PP, (b) PP/talc1, (c) PP/talc2 and (d) PP/talc3. 

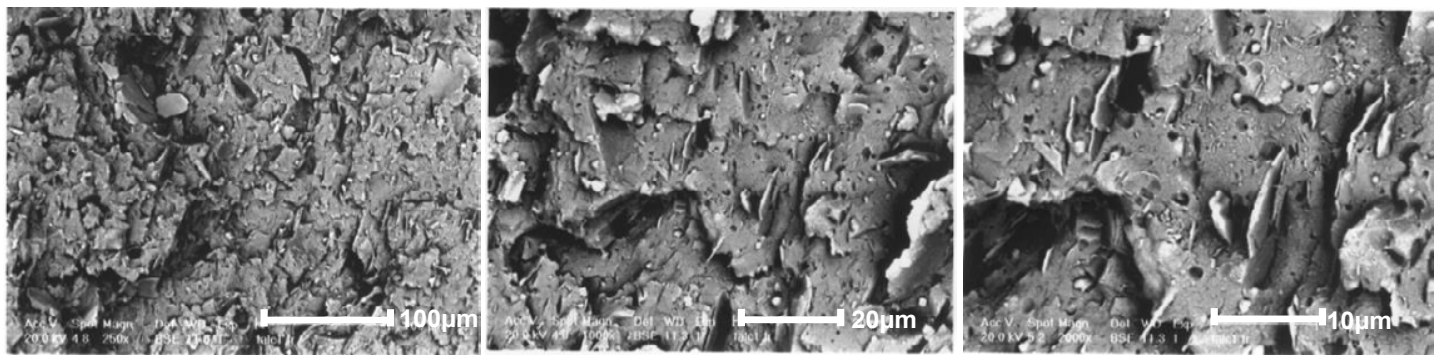

(a)
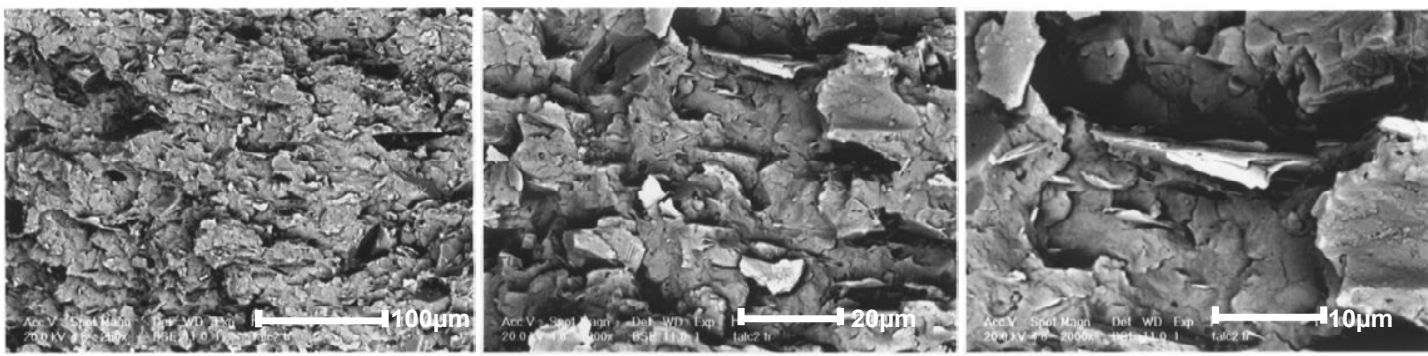

(b)
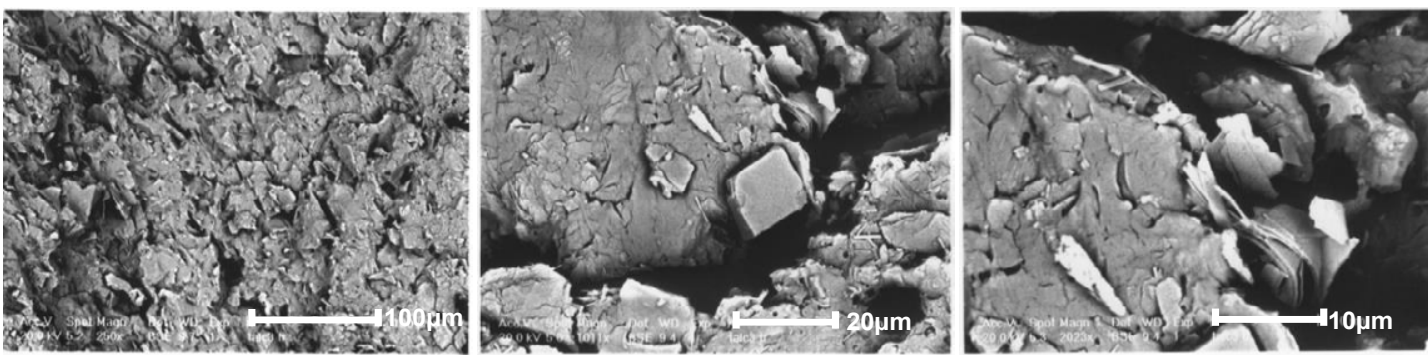

(c)

Figure 4 SEM images of the morphology of compounds (a) PP/talc1, (b) PP/talc2 and (c) PP/talc3.

\section{Influence of the addition of talc on the mechanical properties of PP compounds}

Tensile behavior: The addition of $30 \%$ of talc to the PP matrix affects the mechanical properties of the compound. Indeed, the Young's modulus of the compounds increases with the addition of the mineral filler. As shown in Figure $\mathbf{5 a}$, the elastic modulus of PP/Talc3 is two times higher than the modulus of PP (2736 $\mathrm{MPa}$ versus $1321 \mathrm{MPa})$. Therefore, this rise is the result of the reinforcement's effect of the mineral filler. It is well documented in the literature that composite with mineral fillers has been considered as a useful way to improve the stiffness and that the popular mineral used has been talc [15]. However, the ultimate elongation decreases with the addition of talc (Figure 5b) and is accompanied with the loss of ductility. The PP being the most ductile has the highest elongation at break (63\%). The addition of talc reduces the ductility and therefore the material become brittle (Figure 5c). Indeed, the talc particles act as stress concentrators, embrittling the matrix and consequently reducing the elongation at break [8].

Charpy impact strength: The addition of talc to the PP matrix has for effect a decrease on the Charpy impact strength (Figure
6). The behavior of talc is interesting, it is widely accepted that talc behaves normally, i.e. as a result of its plately nature, talc enhances stiffness even more a carbonate filler, but also degrades impact properties [16]. The unfilled PP wasn't broken; it is ductile with resilience three times higher than the three compounds $\left(120 \mathrm{~kJ} / \mathrm{m}^{2}\right.$ versus $\left.40 \mathrm{~kJ} / \mathrm{m}^{2}\right)$. The unfilled PP, whose fracture is ductile, needs a higher fracture's energy than the composites $\mathrm{PP} /$ talc (brittle fracture). According to the thermal properties discussed previously, adding talc has for result an increase of crystallinity at the expense of amorphous part, which absorbs the impact. In addition, high stress concentrations in the vicinity of filler particles are likely to be detrimental to impact strength [16].

Tenacity: In Figure 7, it was noted that the addition of $30 \%$ of talc to the PP matrix results in a decrease in the critical energy $\mathrm{J}_{\mathrm{Ic}}$. This result is due to the stress concentration effects of the talc. The magnitude of this stress concentration is large for high aspect ratio particles, and thus plately fillers such as talc are likely to suffer more severely from this effect [16]. As a result, the particles of talc facilitate crack's propagation. Because of the large disparities in the elastic and plastic properties of the filler and the matrix, the fillers act as stress concentrators in the PP providing nucleation sites for crack initiation to occur [17]. 


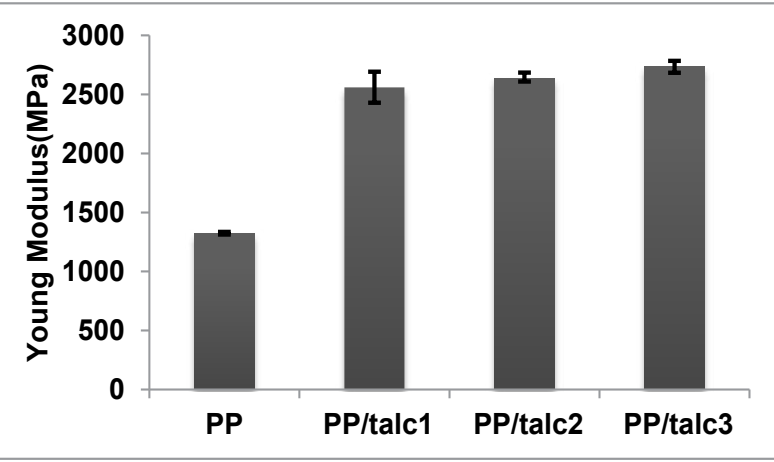

(a)

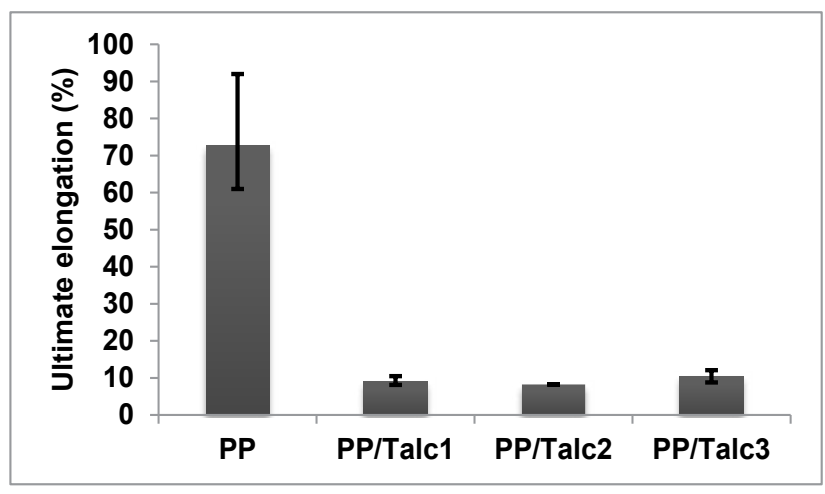

(b)

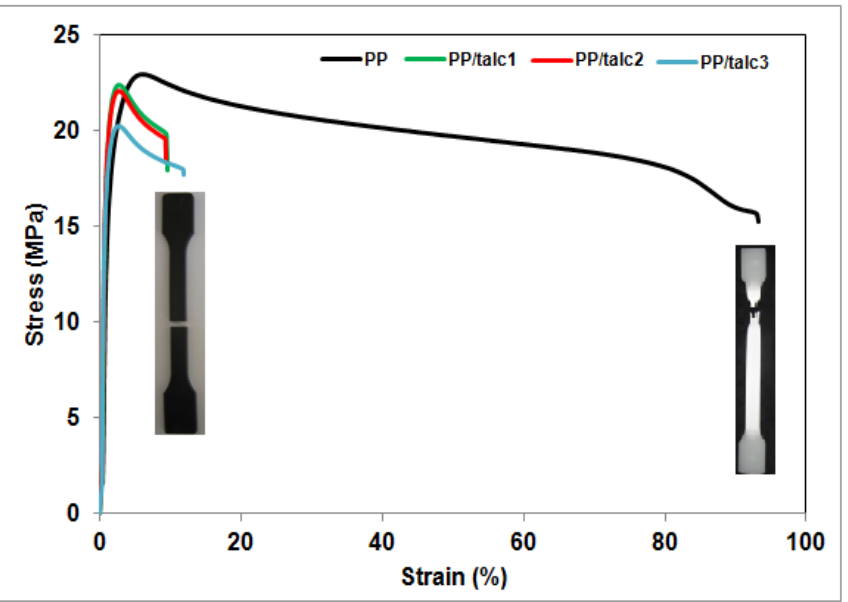

(c)

Figure 5 Effect of the addition of $30 \%$ of talc on (a) tensile behavior (b) Young's modulus and (c) ultimate elongation of PP and PP/talc blend.

Abrasive wear: The wear rate was estimated as follows:

wear rate $=\frac{\left(m_{0}-m_{i}\right) \times 100}{m_{0}}(\%)$

Where $m_{0}$ is the initial mass of the sample and $m_{i}$ is the sample's mass after a period $t(i)$.

The three types of talc don't act with the same way. The extent to which any lamellar solid is abrasive depends upon its intrinsic properties, such as particle size and shape, maximum hardness, etc., and the presence of impurity is also likely to be a major factor
[18]. The compound PP/talc1 has the best abrasive behavior, this result agrees well with the morphological observations; this compound has the best adhesion filler-matrix which gives it a good wear resistance (Figure 8). However, it was noted that talc 3 has a negative effect and the wear rate has been increased; this talc is the most impure and its particles are the biggest $\left(d_{50}=9.5\right.$ $\mu \mathrm{m})$ that causes a bad adhesion between the filler and the matrix, and as a result a facility of particles' extraction and its elimination with water. The compound PP/Talc2 behaves like the unfilled PP, this result is due to a combined effect of purity and the average particle size. Talc1 and talc 2 improve the abrasion's resistance

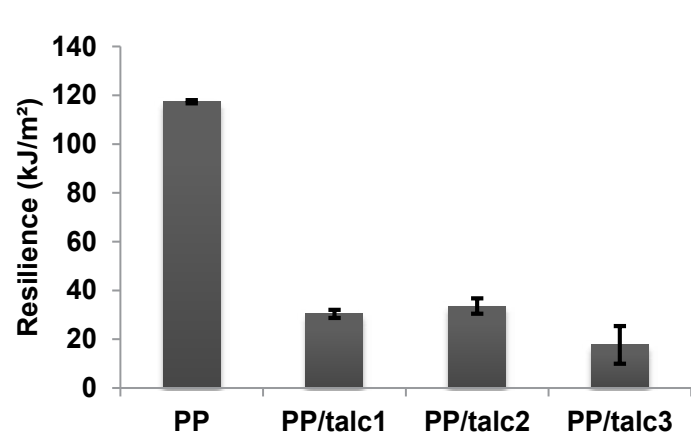

Figure 6 Effect of talc's addition on resilience.

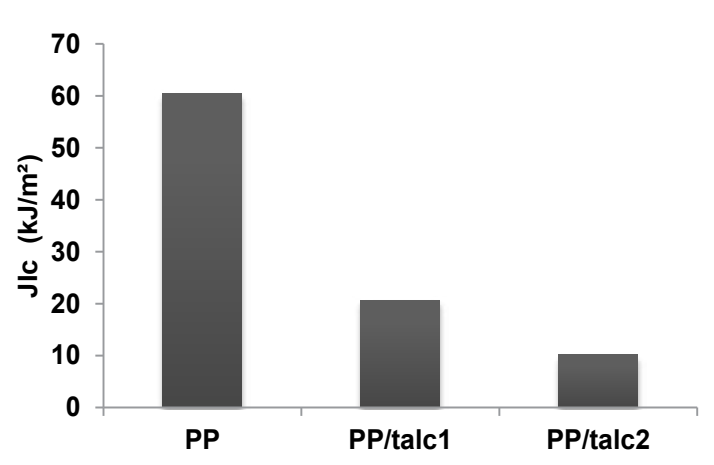

Figure $7 J_{\mathrm{Ic}}$ values of PP and PP/talc (30\%).

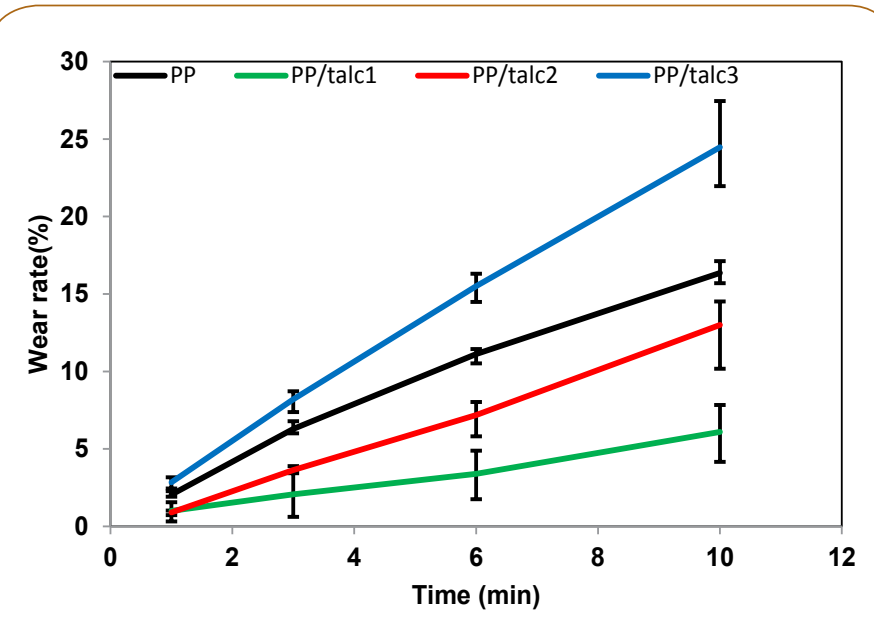

Figure 8 Wear behavior of unfilled PP and the PP/talc blends $(30 \%), F=5 \mathrm{~N}, v=0.29 \mathrm{~m} / \mathrm{s}$. 
of compounds thanks to their behavior as a solid lubricant; talc's platelets facilitate the slip on the interface specimen-abrasive disc. Moreover, the increase of abrasive speed is accompanied with an increase of the wear rate of both unfilled PP and the compound (Figure 9). The wear kinetic has been increased from 8.95 to $16.36 \%$ in about $10 \mathrm{~min}$ for the unfilled PP. This result was due to a decrease in the abrasiveness of the paper (Figure 10) through a degradation of grain at a low speed and however, a good compensation of the intercalation of debris with lubrication at high speed.

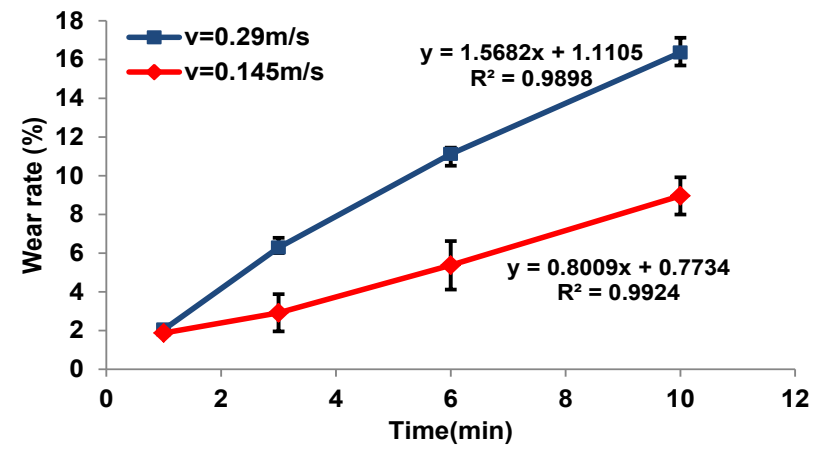

(a)

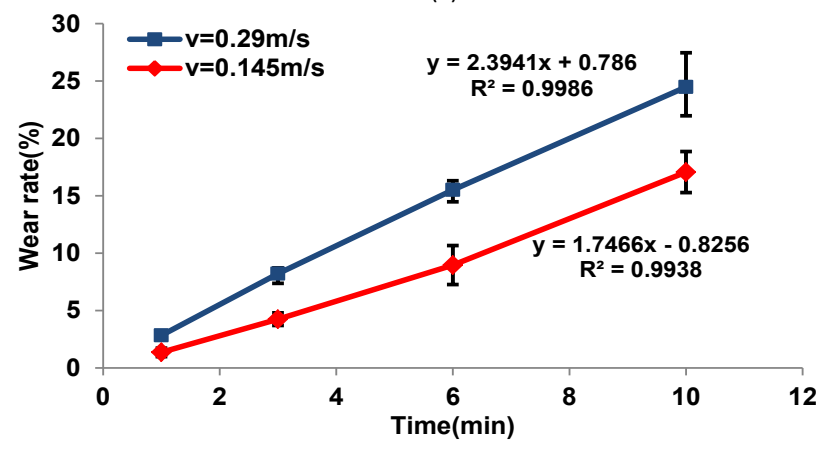

(b)

Figure 9 Evolution of wear rate with variation of rotating speed (a) unfilled PP and (b) PP/talc3 (30\%).

\section{References}

1 Pukanszky B (1995) Particulate filled polypropylene: structure and properties. In Polypropylene structure, blends and composites, Springer Netherlands, pp: 1-70.

2 Bakar MB, Leong YW, Ariffin A, Ishak ZA (2007) Mechanical, flow, and morphological properties of talc-and kaolin-filled polypropylene hybrid composites. Journal of Applied Polymer Science 104: 434-441.

3 Shakoor A, Thomas NL (2014) Talc as a nucleating agent and reinforcing filler in poly (lactic acid) composites. Polymer Engineering \& Science 54: 64-70.

4 Wiebking HE (1996) The performance of ultrafine talc in rigid PVC. Journal of Vinyl and Additive Technology 2: 187-189.

5 Sung YT, Fasulo PD, Rodgers WR, Yoo YT, Yoo Y, et al. (2012) Properties of polycarbonate/acrylonitrile-butadiene-styrene/talc composites. Journal of Applied Polymer Science 124: 1020-1030.

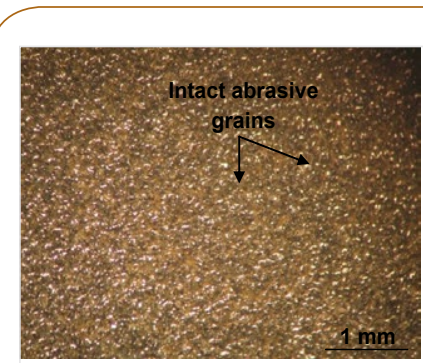

(a)

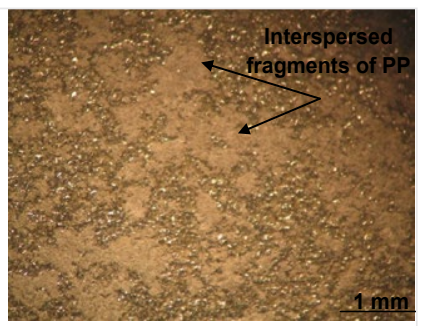

(b)
Figure 10 Abrasive paper (a) before wear experiment and (b) after $5 \mathrm{~min}$ of wear experiment.

\section{Conclusion}

Talc has proved to be particularly efficient on thermal and mechanical properties of the resulting compounds; its use with the polypropylene is very useful especially in industrial applications. Furthermore, the following conclusions were deduced:

1. The dispersion of talc in the PP matrix is uniform and its platelets were aligned along the injection flow direction;

2. Talc addition causes a rising of the PP crystallization temperature and crystallinity. These results indicate that talc is a good nucleating agent;

3. Talc has a positive effect on the stiffness but a deleterious effect on the tensile strength and ductility;

4. Plately fillers such as talc are likely to suffer more severely from the effect of stress concentration. As results, the impact strength and the resistance of crack propagation were decreased;

5. Wear behavior depends essentially on the properties of the particles (especially size) and the purity of talc.

\section{Acknowledgements}

This work was supported by the Ministry of Higher Education and Scientific Research-Tunisia.

6 Qiu W, Mai K, Zeng H (2000) Effect of silane-grafted polypropylene on the mechanical properties and crystallization behavior of talc/ polypropylene composites. Journal of Applied Polymer Science 77: 2974-2977.

7 Fillon B, Thierry A, Lotz B, Wittmann JC (1994) Efficiency scale for polymer nucleating agents. Journal of thermal analysis 42: 721-731.

8 Maiti SN, Sharma KK (1992) Studies on polypropylene composites filled with talc particles. Journal of materials science 27: 4605-4613.

9 Sinha Ray S, Yamada K, Okamoto M, Ueda K (2002) Polylactidelayered silicate nanocomposite: a novel biodegradable material. Nano Letters 2: 1093-1096.

10 McLauchlin AR, Thomas NL (2009) Preparation and thermal characterisation of poly(lactic acid) nanocomposites prepared from organoclays based on an amphoteric surfactant. Polymer Degradation and Stability 94: 868-872. 
11 Menbari S, Ghasemi FA, Ghasemi I (2016) Simultaneous improvement in the strength and toughness of polypropylene by incorporating hybrid graphene/CaCO3 reinforcement. Polymer Testing 54: 281-287.

12 Ferrage E, Martin F, Boudet A, Petit S, Fourty G, et al. (2002) Talc as nucleating agent of polypropylene: morphology induced by lamellar particles addition and interface mineral-matrix modelization. Journal of Materials Science 37: 1561-1573.

13 Zhou XP, Xie XL, Yu ZZ, Mai YW (2007) Intercalated structure of polypropylene/in situ polymerization-modified talc composites via melt compounding. Polymer 48: 3555-3564.

14 Gonzalez A, de Saja JA, Alonso M (1995) Morphology and tensile properties of compression-moulded talc-filled polypropylene. Plastics, Rubber \& Composites Processing and Appl 3: 131-137.
15 Azuma Y, Takeda H, Watanabe S, Nakatani H (2009) Outdoor and accelerated weathering tests for polypropylene and polypropylene/ talc composites: A comparative study of their weathering behavior. Polymer Degradation and Stability 94: 2267-2274.

16 McGenity PM, Hooper JJ, Paynter CD, Riley AM, Nutbeem C, et al. (1992) Nucleation and crystallization of polypropylene by mineral fillers: relationship to impact strength. Polymer 33: 5215-5224.

17 Sole BM, Ball A (1996) On the abrasive wear behaviour of mineral filled polypropylene. Tribology International 29: 457-465.

18 Grattan PA, Lancaster JK (1967) Abrasion by lamellar solid lubricants. Wear 10: 453-468. 